\title{
DISEASE PANDEMICS AND THE THREAT OF MICROBIAL EMERGENCE
}

\author{
Lalit Kant, Gifty Immanuel and Jai Prakash Narain
}

\section{Introduction}

Climate is fundamental to life on earth and has a powerful impact on human health. Climate change-related infectious diseases have been evolving and spreading to areas that were, until now, free of them. Amongst infectious diseases, zoonotic diseases - those transmitted from animals to humans - are particularly impacted by climate change. Caused by viruses, bacteria, parasites, etc., zoonotic diseases are said to be responsible for $60 \%$ of all infectious diseases in humans, and $75 \%$ of all emerging infectious diseases (Cunningham, 2005). This chapter will explore:

1. How climate change has influenced the emergence of novel viruses following "cross-over," to which the human race has no immunity.

2. The profound implications in terms of health security and disease control following the emergence of disease-causing microbes that present an unprecedented challenge to global health.

3. How epidemics, pandemics and climate change affect humans, and the appropriate responses to these threats.

\section{Links between climate change and zoonoses}

In 2019, the world's population was about 7.5 billion. It took 200,000 years to reach the first billion, and only another 200 years to reach 7 billion (AMNH, 2016). In order to meet the food requirements and other needs of billions of people, human activities such as burning of fossil fuels (oil, coal, natural gas, etc.) for energy have increased manifold, releasing large amounts of greenhouse gases into the atmosphere. In addition, industrialisation, urbanisation, mining activities, logging, livestock farming and clearing of forests for the construction of infrastructure such as roads or dams, etc., have all forced a large number of animals to migrate to peri-urban areas in close proximity to human habitats.

Together, human activities and climate change inter alia drive wild animals closer to populated areas, creating opportunities for pathogens to 
move from animals to humans. If microbes are able to adapt themselves for efficient human-to-human transmission, the risk for an epidemic or a pandemic increases. According to an International Livestock Research Institute study, 13 zoonoses have been the cause of 2.4 billion cases of human disease and 2.2 million deaths per year, with the highest zoonotic disease burden in Ethiopia, Nigeria, Tanzania, and India (Grace et al., 2012). The true burden is difficult to estimate due to underreporting and under-diagnosis.

\section{New and emerging zoonotic diseases}

A previous chapter has discussed the evidence of a rise in atmospheric temperatures leading to the increased transmission of disease. Warmer temperatures and changes in rainfall have created favourable conditions for vectors and pathogens in some areas that did not previously support their survival. The glaciers, permafrost, icebergs, frozen lakes and seas that constitute the earth's cryosphere are highly sensitive to global warming (Margesin and Collins, 2019). Pathogens can transmit through environmental pathways with melted water and contaminated surfaces as a medium of transfer. Currently, about $37 \%$ of the northern hemisphere is covered by circumpolar permafrost (Dobricic and Pozzoli, 2019). 35 million people live in these permafrost zones (Oliva and Fritz, 2018). At the rate of global warming, a $60 \%$ thaw can be expected by 2100 (Biskaborn et al., 2019). Melting glaciers and thawing permafrost can release hidden microbes buried under layers of ice for long periods of time. The microbial threats arising from such melting repositories in ice pose a significant danger to human and animal health. Thawing could bring the host (such as humans and animals) in proximity to the contagion, facilitating transmission. Essentially, two scenarios could emerge: one is the re-emergence of known microbes, such as Bacillus anthracis, which caused a recent outbreak in reindeer herds and humans in Siberia (Stella et al., 2020); the other is the resurrection of previously unknown viruses, such as the giant virus Pithovirus sibericum with unknown infectivity that was isolated from a 30,000-year-old block of ice (Okamoto et al., 2017).

These hotspots of disease emergence are less visible but are increasingly relevant to global health.

\section{Viral threats}

Viruses are formidable disease-causing agents with a potential for largescale pandemics. The COVID-19 pandemic (discussed further on in the chapter) is caused by the virus now known as the Severe Acute Respiratory Syndrome Coronavirus 2 (SARS-CoV-2). The Spanish Influenza (H1N1A) killed nearly 40 million people worldwide in 1918. In a recent study, victims of the 1918 Spanish influenza who had been buried in a mass grave in the permafrost in Alaska were exhumed for analysis (Reid et al., 1999). Positive 
RNA material of the virus could be retrieved from their bodies. This finding presents a bleak scenario: that thawing permafrost can unearth corpses that harbour such lethal viruses. Increased human activity in such zones can amplify the chances of viral infection and spread. Similarly, the DNA of the smallpox virus Variola major was isolated from a 300-year-old corpse mummified in Siberian permafrost (Edwards, 2015). Meanwhile, migratory birds and artic penguins can deposit Influenza viruses in frozen lakes, which then act as reservoirs releasing viruses when they melt (Edwards, 2015).

\section{Bacterial threats}

Until recently, cold habitats were considered pristine environments. Studies involving sampling of ice and soil have shown antibiotic-resistant genes (Segawa et al., 2013). Temperature tolerant Escherichia coli and Streptococcus fecalis are frequently sampled in meltaway waters, increasing the chances of feco-oral transmission among polar tourists and climbers (Segawa et al., 2013). Cholera is a well-known climate-sensitive pandemic with a high mortality rate (Box 5.1). Meanwhile, the recovery of multiple antibiotic-resistant bacteria from the Siachen glacier poses a unique threat to the Indian sub-continent (Rafiq et al., 2017). Increased human activity, migratory birds and airborne dissemination have been suggested as drivers of disease emergence. These frozen zones can also act as reservoirs of

\section{Box 5.1 Case study \\ Weather satellite networks: An early warning system against pandemics}

NASA space technology is being used as an epidemiological tool for disease control, surveillance and prevention. Weather tracking satellites can help forecast disease emergence based on atmospheric, land and weather data. In 2017, NASA Earth-observing research satellites used machine learning and a Cholera Prediction Modeling System to predict with $92 \%$ accuracy, an evolving outbreak of cholera in Yemen (Figure 5.1). Several deaths were averted due to the early warning system and subsequent activation of field level initiatives. This disease prediction model was able to integrate the precipitation data, ocean temperatures and phytoplankton movements (phytoplankton - a marine algae - are reservoirs of the cholera bacteria). This free resource is of potential value to decision-makers by providing forecast and lead times. The programme is funded by the NASA Applied Sciences that permits all international institutions and individuals to use NASA data for disease prediction and forecast. 


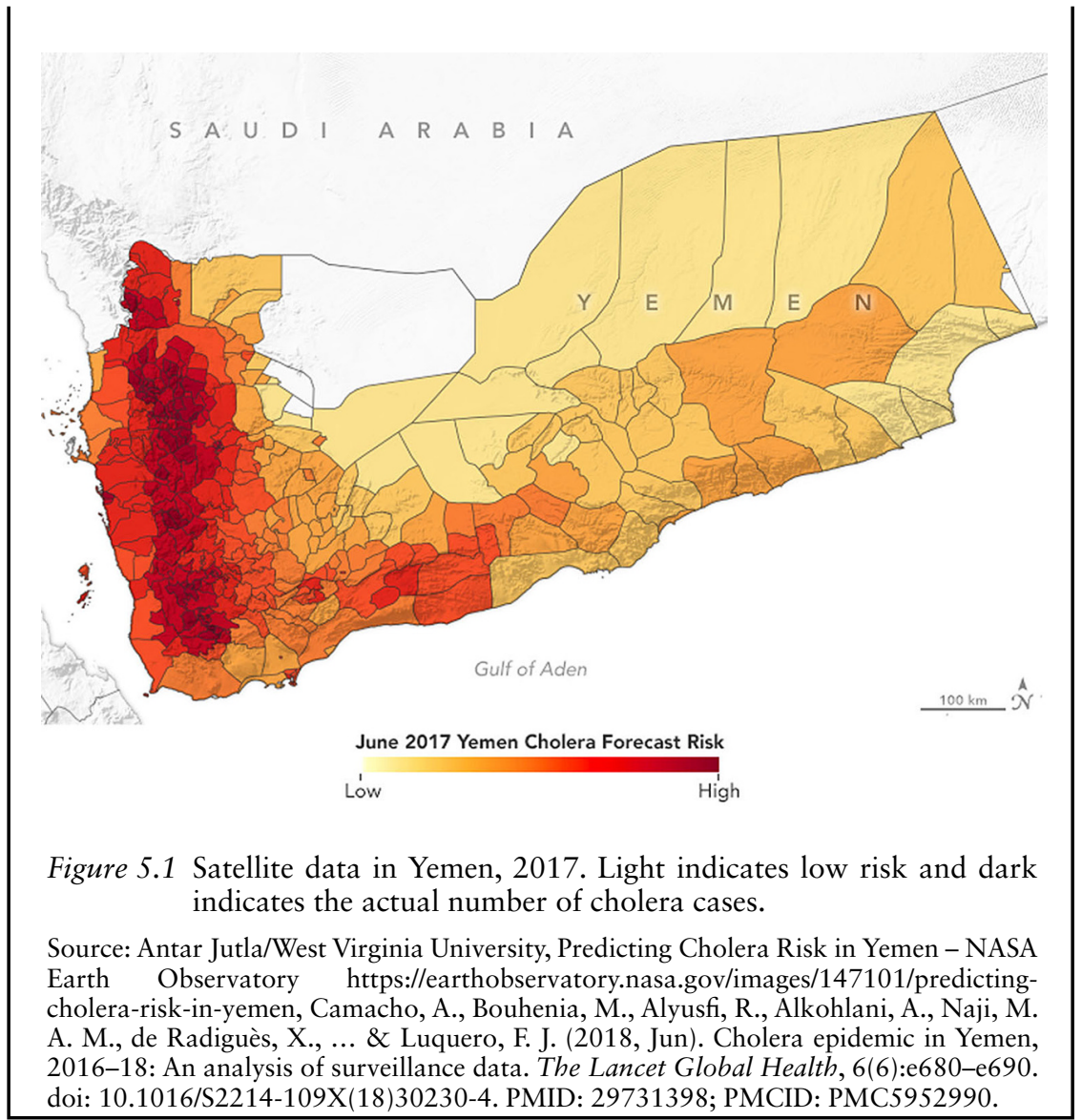

pathogenic drug-resistant bacteria impeding global measures to contain antimicrobial resistance (AMR). Another possibility is the release of lethal bacteria like Bacillus anthracis (described earlier) into human and animal populations with fatal consequences.

\section{Fungal threats}

Environmental fungi like Cryptococcus are notorious pathogens for the immuno-compromised (these could include people living with HIV/AIDS, those with kidney and liver diseases, those undergoing organ/stem cell transplants, and those undergoing cancer therapy) and, to a lesser extent, to a healthy population. Aureobasidium pullulans is another cold-adapted environmental fungus of medical importance due to its resistant nature (Edwards, 2015). Similarly, Candida auris is an emerging super fungus that displays multidrug resistance and is a major pathogen in hospital intensive care units. Fungal communities preserved in ice have undergone "adaptation" to higher 
temperatures as a result of global warming. This strategically helps them in overcoming human thermal barriers (Edwards, 2015).

The emergence of the West Nile virus, Rift Valley fever and Dengue fever in new geographical areas has been linked with the El Nino oscillation (Githeko et al., 2000). While Africa witnessed the emergence of new viruses like HIV, Ebola haemorrhagic fever and Rift Valley fever, South America saw a rise in the Zika virus. In North America, in particular the US, the zoonotic diseases of influenza, salmonellosis, West Nile virus, plague, emerging coronaviruses, rabies, brucellosis and Lyme disease have been listed as those of greatest concern (CDC, 2017). The avian flu (H5N1), SARS and Nipah viruses appeared in Asia. Europe saw a rise in cases of Tularaemia, Haemorrhagic fever with renal syndrome, Tick-borne encephalitis, Mad Cow disease, and West Nile fever (Vorou et al., 2007).

In India, the major public health zoonotic diseases are rabies, brucellosis, toxoplasmosis, cysticercosis, echinococcosis, Japanese Encephalitis (JE), leptospirosis, Scrub typhus, Nipah, Kyasanur forest disease (KFD) and Crimean-Congo haemorrhagic fever (Dhiman and Tiwari, 2018).

Among zoonotic viruses, influenza has led to the largest number of epidemics and even pandemics. Influenza viruses are found in humans and animals. These are of four types: Influenza A, B, C and D viruses. Influenza $\mathrm{A}$ has been responsible for seasonal epidemics and pandemics, and Influenza B causes only seasonal epidemics. Climate changes that influence wild waterbird habitats, migration, and stopover sites could be a factor in the global distribution of avian virus agents and possibly the emergence of a new pandemic influenza strain. Influenza viruses, by nature, are constantly evolving in multiple species and many different genetic and antigenic groups. A future pandemic of influenza is a strong possibility, although the timing and location are uncertain. As seen in Table 5.1, influenza viruses have been the cause of four pandemics in history (Dauphin, 2015).

In order to detect a potential pandemic influenza strain, the World Health Organization, the Food and Agriculture Organization, and the World Organization for Animal Health work together through a number of

Table 5.1 Pandemics caused by Influenza viruses

\begin{tabular}{llllll}
\hline Year & Strain & $\begin{array}{l}\text { Origin of } \\
\text { virus }\end{array}$ & $\begin{array}{l}\text { Pandemic } \\
\text { started in }\end{array}$ & $\begin{array}{l}\text { Name of } \\
\text { pandemic }\end{array}$ & Deaths \\
\hline 1918 & A(H1N1) & Avian & China & Spanish flu & $40-50 \mathrm{~m}$ \\
1957 & A(H2N2) & Avian & China & Asian flu & $1-2 \mathrm{~m}$ \\
1968 & A(H3N2) & Avian & China & Hong Kong flu & $0.5-2 \mathrm{~m}$ \\
2009 & A(H1N1) & Swine & Mexico & Pandemic flu & $\sim 0.57 \mathrm{~m}$ \\
\hline
\end{tabular}

$\mathrm{m}=$ million 
Table 5.2 Epidemics and pandemics caused by Coronaviruses

\begin{tabular}{llllllll}
\hline Year & Name & $\begin{array}{l}\text { Outbreak } \\
\text { started in }\end{array}$ & $\begin{array}{l}\text { Natural } \\
\text { host }\end{array}$ & Via & $\begin{array}{l}\text { Countries } \\
\text { affected }\end{array}$ & Cases & Deaths \\
\hline 2003 & SARS & China & Bat & $\begin{array}{c}\text { Civet } \\
\text { cat }\end{array}$ & 29 & $>8000$ & $>770$ \\
2012 & MERS & $\begin{array}{c}\text { Saudi } \\
\text { Arabia }\end{array}$ & Bat & Camel & 27 & $>2500^{\mathrm{a}}$ & $>800^{\mathrm{a}}$ \\
2019 & COVID-19 & $\begin{array}{c}\text { China } \\
\text { China }\end{array}$ & Bat & $?$ & $188^{\mathrm{b}}$ & $>16.7 \mathrm{m \#}$ & $>0.66 \#$ \\
\hline
\end{tabular}

aas of 31 March 2020; bcontinuing; \# as of 30 July 2020; m=million (Source of COVID-19 data: https://coronavirus.jhu.edu/map.html)

established detection and response frameworks (Saunders-Hastings and Krewski, 2016).

Another group of viruses that has been the cause of epidemics, and the most recent pandemic, are the coronaviruses. Coronaviruses are a group of viruses that cause diseases in animals and humans. A diverse array of bat and bird species are believed to be their natural hosts. They often circulate among animals such as camels, cats, cows, pigs etc. To date, seven coronaviruses have the ability to cause disease in humans. Four are endemic and usually cause mild disease, (regularly found and responsible for about $10-15 \%$ of common colds) but three (SARS, MERS and COVID-19) have caused severe disease. Table 5.2 gives further details.

The pandemic of COVID-19, resulting from a novel coronavirus named SARS-CoV-2, like SARS in 2002, also emerged from China (WHO, 2019). It has proven to be a highly contagious disease that spread around the world within a few weeks and devastated nations as never before. As a result of lockdown implemented by many countries to suppress the virus, schools, workplaces, shops and factories were shut, travel restricted and flights grounded for a long period of time. The tragedy unfolded in countries across the globe, causing untold misery and economic meltdown.

\section{Overlaps between pandemics and climate change in terms of impact and responses}

Although a pandemic like COVID-19 presents different challenges compared to climate change, there are many parallels between them. Pandemics know no boundaries, and neither do the effects of climate change. Both are a global problem with local consequences; addressing them requires a collaborative and coordinated set of solutions implemented locally, nationally, regionally and internationally. Their health and economic consequences are unequivocal and severe. Both are linked to human behaviour. Clearly, early action on both can save lives and any delay in response can increase the human and socioeconomic costs many times over. 
Pandemics and climate change both essentially impact all sectors of society and require concerted action that engages the "whole of society" in response. Both pandemics and climate change disproportionately impact those who are most vulnerable and marginalised in society - the poor, the old and the young, and those who have no or limited access to health services. Both trigger obligations of governments and others to protect them.

When faced with public health threats of a global scale, such as COVID-19 or climate change, nations are only as strong as their weakest health system. Universal health coverage through well-resourced and equitable health systems is essential in order to protect the public from both short- and longterm health threats. The global community has shown that it can act to address a crisis, by taking measures and changing behaviours in response to COVID-19. Faced with the multifaceted impacts of COVID-19 and climate change, multilateralism is the only way forward, requiring not only political commitment and use of science for policymaking, but also for all to unite as a single global community and respond in a coordinated manner.

Given that pandemics and climate change affect multiple sectors of society, countries need broad and sustainable multisectoral preparedness and response plans that outline their policies, strategies and operations to manage these emergencies. Social protection programmes are already in operation to help manage the risks and impacts of weather and climate extremes on the most vulnerable people (Kuriakose et al., 2013). This has been done in drought areas through cash transfers to vulnerable households. Similar social safety programmes have been effectively used to soften the twin health and economic shocks of COVID-19 (Gilligan, 2020).

To tackle both pandemics and climate change, it is important to have the capacity and capabilities to detect unusual events through an early warning system in order to mount an effective response. Examples of some global initiatives include:

- The Global Climate Observing System: Established in 1992 to ensure that the observations and information needed to address climate-related issues are obtained and made available to all users, this system integrates satellite observations, ground-based data and forecast models to monitor and forecast changes in the weather and climate.

- The Global Early Warning System for Major Animal Diseases including Zoonosis (GLEWS): In 2006, OIE, FAO, and WHO consolidated efforts to establish GLEWS. It became one of the mechanisms used for monitoring data from existing event-based surveillance systems and to track and verify relevant animal and zoonotic events.

- The Global Outbreak Alert and Response Network (GOARN): In 2000 , the WHO established the GOARN as a network of networks. It pools human and technical resources from more than 100 institutions around the world to rapidly identify, confirm, and respond to outbreaks of international importance. 
In India, the human component of zoonotic disease surveillance is steered by the National Centre for Disease Control, while the animal component is undertaken by the Indian Council of Agricultural Research.

Though pandemics and climate change share similarities, there are also differences. A pandemic is a natural or biological phenomenon, often caused by emergence of a new or novel pathogen against which people have no immunity. Its impact is generally of a shorter duration. On the other hand, climate change is a man-made disaster, a slow-moving tsunami. The threat from events linked to climate change will play out over longer timeframes.

\section{Learnings from pandemic control efforts for climate change}

The 2020 coronavirus pandemic has shown that political leadership and planning is critical, and that governments can even implement unpopular policies like lockdowns, in the interest of the public good. Radical changes are possible and can be taken quickly. Many of these have been transformative in the way that society lives and works. For example, working from home has contributed, at least temporarily, to reduced air pollution. Likewise, transformative changes are required in order to address climate change. As with COVID-19, several world leaders believed that climate change would not affect them as a nation. This perception needs to be countered. Governments must act with the same extraordinary co-operation and comprehensiveness against climate change, for which they acted against COVID-19. Calls and examples of collaboration and solidarity multiplied in the first few months of the coronavirus pandemic, and it is time that similar things were done for climate change as well. Well-resourced healthcare systems providing universal healthcare are essential for protection health threats of climate change. Trillions of US\$ will be spent globally in the next year or so to help jumpstart the economy. This stimulus should comprise green initiatives.

\section{The role of healthcare professionals}

Healthcare professionals have an important role to play - educating the patients and their families about the harmful effects of climate change on human health, and what they can do to minimise the impact. As trusted members of society, health professionals have both the authority and expertise to encourage the community to follow government advisories during pandemics as well as those for climate change. During the COVID-19 pandemic, if every person practiced preventive steps such as using masks correctly, maintaining physical distance, and frequently washing hands with soap and water, people can individually and collectively limit disease transmission to a great extent. Avoiding crowded public transport in favour of walking or using bicycles have the co-benefits of preventing COVID-19 as well as improving one's own health. Likewise, minimising the use of fossil 
fuels by switching to renewable energy sources like solar power, etc. can help decrease global warming.

One cannot and must not underestimate the power of social responsibility in reducing global warming and the spread of epidemics. Being socially responsible means that everyone needs to do their part, and that every person can make a difference.

\section{Key takeaways}

- Human wellness is inextricably linked to planetary health.

- Individually and collectively, humans have contributed to creating ecological conditions for zoonotic diseases to emerge and spread, while also being responsible for loss of biodiversity and consumption of fossil fuel leading to climate change.

- Earth's cold zones are massive repositories of microbes posing the threat of disease outbreaks. Permafrost microbes play a central role in climate change biology as well as disease emergence.

- Increased human activity and animal migration patterns have led to the deposition of antibiotic-resistant, highly lethal and exotic pathogens in these habitats.

- Next-generation methods need to be adopted to address this crisis.

- Raging zoonotic diseases, such as the pandemic Influenza of 1918 or COVID-19, are wake-up calls to the global community on the ultimate cost of inaction on the rapidly unfolding climate crisis.

- The human response to pandemics can demonstrate how to mount a more efficient response to threats of climate change. Everyone should proactively contribute to meet the dual challenge.

- It would be irresponsible to wait until the climate crisis reaches epidemic or pandemic proportions. In fact, addressing climate change now is in itself a mitigation action against future epidemics and pandemics.

\section{References}

American Museum of Natural History. (2016). Human population through time. https://www.amnh.org/content/search?SearchText=human+population+through+ time

Biskaborn, B. K., Smith, S. L., Noetzli, J., Matthes, H., Vieira, G., Streletskiy, D. A., ... \& Lantuit, H. (2019). Permafrost is warming on a global scale. Nature Communications, 10, 264.

Camacho, A., Bouhenia, M., Alyusfi, R., Alkohlani, A., Naji, M. A. M., de Radiguès, X., \& Luquero, F. J. (2018, Jun). Cholera epidemic in Yemen, 2016-18: An analysis of surveillance data. The Lancet Global Health, 6(6), e680-e690. doi: 10.1016/ S2214-109X(18)30230-4. PMID: 29731398; PMCID: PMC5952990.

CDC. (2017). Prioritizing zoonotic diseases for multisectoral, One Health collaboration in United States. Workshop summary. https://www.cdc.gov/onehealth/pdfs/ us-ohzdp-report-508.pdf 
Cunningham, A. A. (2005). A walk on the wild side - Emerging wildlife diseases. $B M J, 331,1214-1215$. doi: 10.1136/bmj.331.7527.1214

Dauphin, P. G.. (2015). WHO/FAO/OIE tripartite coordination for the control and prevention of zoonotic influenza viruses. Example of OFFLU, global network of veterinary expertise. Bulletin de l'academie Veternaire de France, 168(3). doi: $10.4267 / 2042 / 57932$.

Dhiman, R. C., \& Tiwari, A. (2018) Emergence of zoonotic diseases in India: A systematic review. Medical Reports and Case Studies, 3, 3. doi: 10.4172/2572-5130.1000163.

Dobricic, S., \& Pozzoli, L. (2019). Arctic permafrost thawing, UR 29940 EN, Publications Office of the European Union, Luxembourg, 2019, ISBN 978-9276-10182-6, doi: 10.2760/007066, JRC109379.

Edwards, A. (2015). Coming in from the cold: Potential microbial threats from the terrestrial cryosphere. Frontiers in Earth Science, 3, 12. doi: 10.3389/feart.2015. 00012

Gilligan, D.. (2020, June) Social safety nets are crucial to the COVID-19 response. Some lessons to boost their effectiveness. International Food Policy Research Institute. https://www.ifpri.org/blog/social-safety-nets-are-crucial-COVID-19-responsesome-lessons-boost-their-effectiveness

Githeko, A. K., Lindsay, S. W., Confalonieri, U. E., \& Patz, J. A. (2000). Climate change and vector-borne diseases: A regional analysis. Bulletin of the World Health Organization, 78(9), 1136-1147.

Grace, D., Mutua, F., Ochungo, P., Kruska, R., Jones, K., Brierley, L., Lapar, L., Said, M., Herrero, M., Phuc, P. M., Thao, N. B., Akuku, I., \& Ogutu, F. (2012). Mapping of poverty and likely zoonoses hotspots. Zoonoses Project 4. Report to the UK Department for International Development. ILRI. https://hdl.handle.net/10568/21161

Kuriakose, A. T., Heltberg, R., Wiseman, W., Costella, C., Cipryk, R., \& Cornelius, S. (2013). Climate-responsive social protection. Development Policy Review, 31(S2), o19-o34. https://www.climateinvestmentfunds.org/sites/default/files/Kuriakose_et_ al_2013.pdf

Margesin, R., Collins, T. (2019). Microbial ecology of the cryosphere (glacial and permafrost habitats): Current knowledge. Applied Microbiology and Biotechnology, 103, 2537-2549. doi: 10.1007/s00253-019-09631-3

Okamoto, K., Miyazaki, N., Song, C., Maia, F. R., Reddy, H. K., Abergel, C., ... \& Murata, K. (2017). Structural variability and complexity of the giant Pithovirus sibericum particle revealed by high-voltage electron cryo-tomography and energyfiltered electron cryo-microscopy. Scientific Reports, 7, 13291.

Oliva, M., \& Fritz, M. (2018). Permafrost degradation on a warmer Earth: Challenges and perspectives. Current Opinion in Environmental Science of Health, 5, 14-18.

Rafiq, M., Hayat, M., Anesio, A. M., Jamil, S. U. U., Hassan, N., Shah, A. A., \& Hasan, F. (2017). Recovery of metallo-tolerant and antibiotic resistant psychrophilic bacteria from Siachen glacier, Pakistan. PLOS ONE, 12(7), e0178180. doi: 10.1371/journal.pone.01781

Reid, A. H., Fanning, T. G., Hultin, J. V., \& Taubenberger, J. K. (1999, February 16). Origin and evolution of the 1918 "Spanish" influenza virus hemagglutinin gene. PNAS, 96(4), 1651-1656. doi: 10.1073/pnas.96.4.1651 
Saunders-Hastings, P. R., \& Krewski, D. (2016). Reviewing the history of pandemic influenza: Understanding patterns of emergence and transmission. Pathogens, 5(4), 66. doi: 10.3390/pathogens5040066

Segawa, T., Takeuchi, N., Rivera, A., Yamada, A., Yoshimura, Y., Barcaza, G., ... \& Ushida, K. (2013). Distribution of antibiotic resistance genes in glacier environments. Environmental Microbiology Reports, 5, 127-134. doi: 10.1111/17582229.12011

Stella, E., Mari, L., Gabrieli, J., Barbante, C., \& Bertuzzo, E. (2020). Permafrost dynamics and the risk of anthrax transmission: A modelling study. Scientific Reports, 10, 16460.

Vorou, R. M., Papavassiliou, V. G., \& Tsiodras, S. (2007). Emerging zoonoses and vector-borne infections affecting humans in Europe. Epidemiology \& Infection, 135(8), 1231-1247. doi: 10.1017/S0950268807008527

WHO. (2019). Coronavirus disease 2019 (COVID-19) situation report-94. https:// www.who.int/docs/default-source/coronaviruse/situation-reports/2020 0423-sitrep-94-COVID-19.pdf 